\title{
HISTÓRIA DO FEDERALISMO FISCAL NO BRASIL IMPÉRIO: TEXTO E CONTEXTO NAS DELIBERAÇÕES LEGISLATIVAS DO ATO ADICIONAL DE 1834
}

\author{
HISTORY OF FISCAL FEDERALISM IN BRAZIL EMPIRE: TEXT AND \\ CONTEXT IN LEGISLATIVE DELIBERATIONS OF THE ADDITIONAL ACT OF \\ 1834
}

\author{
${ }^{1}$ Guilherme Dourado Aragão Sá Araujo \\ ${ }^{2}$ Maria Lírida Calou de Araújo e Mendonça
}

\section{RESUMO}

O presente trabalho expõe a influência da centralização política francesa no Brasil em contraponto com a influência da doutrina federalista norte-americana na década de 1830. Por meio de pesquisa historiográfica e da análise estudos financeiros e de documentos político- legislativos do Império, aborda o movimento descentralizador da década de 1830, que culminou no surgimento do federalismo fiscal no Brasil, e que já à época apresentava muitos dos problemas que persistem à contemporaneidade. Ao final, conclui-se que o movimento descentralizador no Brasil Império foi inspirado no federalismo norte-americano, mas que fracassou em cuidar da autonomia financeira das Províncias.

Palavras-chave: História do direito, História do brasil, Federalismo fiscal, Ato adicional de 1834

\begin{abstract}
The present work exposes the influence of French political centralization in Brazil contrasted with the influence of north-American federalist doctrine in the 1830s. Through historiographical research and the analysis of financial studies and political and legislative documents of the Empire, it addresses the decentralization movement on the 1830s, which enabled the origins of fiscal federalism in Brazil, and that at the time it already exhibit many of the problems that persists to nowadays. Finally, it is concluded that the decentralization movement on Brazil Empire was inspired by northAmerican federalism, but that it failed in taking account of the Provinces finances.
\end{abstract}

Keywords: History of law, History of brazil, Fiscal federalism, Additional act of 1834

\footnotetext{
${ }^{1}$ Mestre em Direito Constitucional pela Universidade de Fortaleza - UNIFOR, Ceará (Brasil). Professor do Centro Universitário Católica de Quixadá - UNICATÓLICA, Quixadá - CE (Brasil). E-mail: gdourado@edu.unifor.br

${ }^{2}$ Doutora em Direito pela Universidade Federal de Pernambuco - UFPE, Recife - PE (Brasil). Professora da Universidade de Fortaleza - UNIFOR, Ceará (Brasil). E-mail: liridacalou@unifor.br
} 


\section{INTRODUÇÃO}

O presente artigo aborda as influências politico-culturais da França, com sua administração centralizada, e dos Estados Unidos, com sua administração descentralizada, em meio à tentativa de imposição do regime federalista no Brasil Império por meio do Ato Adicional de 1834. Por meio de pesquisa historiográfica e bibliográfica e da análise estudos financeiros e de documentos político-legislativos do Império, demonstra-se o contexto histórico do surgimento do movimento federalista no Brasil e seu resultado: o Ato Adicional de 1834.

Como objetivo geral tem-se a análise do surgimento do federalismo fiscal e da autonomia financeira das Províncias no Brasil Império a partir do Ato Adicional de 1834. De forma específica, serão abordadas primeiramente as influências contrapostas da centralização francesa e do federalismo norte-americano no Brasil. Posteriormente, trata da além da adaptação do modelo descentralizado ao panorama do Brasil Império por meio das deliberações que resultariam no referido Ato.

Ao final, demonstra-se que a desejada - e alardeada - autonomia financeira das Províncias não pôde ser concretizada em virtude de uma má distribuição de competências tributárias e administrativas - e da ausência de um eficiente sistema de repartição de receitas.

\section{O CONCEITO DE FEDERALISMO COMO UM VEÍCULO DA (DES)CENTRALIZAÇÃO}

Engana-se quem conceitua federalismo como um movimento pela descentralização das atribuições políticas ou administrativas. Existe, em geral, uma ideia equivocada de que referido sistema de organização do Estado se caracterizasse - e se conceituaria por isso por uma peculiar objetivo de descentralizar o poder central: tratam o federalismo como uma doutrina descentralizadora.

Esse equívoco parece advir da doutrina europeia, que, tendo-lhe trabalhado mais de forma teórica que prática - por não ter o federalismo sido imediatamente importado da América - acabou por incorporar seu contexto de forma equivocada em uma teoria surgida em meio a um cenário político-social completamente distinto. 
Muito se repete que o federalismo brasileiro teria surgido a partir da União em direção aos Estados, enquanto o americano teria surgido a partir dos Estados para a União sem que, entretanto, se perceba quais as implicações disso.

Por se tratar de um peculiar sistema político teorizado e proposto antes de sua aplicação efetiva, ao contrário do desenvolvimento natural e espontâneo de outros sistemas políticos surgidos da prática e dos costumes, existe a vantagem de se poder estudar sua fundação diretamente a partir de sua mente criadora, e, portanto, compreender melhor o que se quis e como se quis fazer: pela obra de Madison, Jay e Hamilton (2001).

A teorização do federalismo nos Estados Unidos da América não teve por objetivo uma descentralização do poder político, ao contrário do que se costuma entender. Embora seja entendido como uma alternativa à concentração do poder e da administração, o federalismo foi desenvolvido, ao contrário, com objetivo de conferir mais poderes à autoridade central, que seria representada na "União" de todas as colônias.

Imediatamente após a independência das treze colônias britânicas na América do Norte e o fim da respectiva guerra, os Estados se reuniram em diversas Confederações ${ }^{1}$ independentes entre si mas reunidas pelo que se denominou Artigos da Confederação, de 1778, que era uma espécie de tratado internacional entre as antigas colônias.

A fragilidade desse laço foi desde logo percebida como uma possível vulnerabilidade da nação recém criada ao enfrentar possíveis ameaças internas e, principalmente, externas. O risco de uma invasão estrangeira é uma das maiores preocupações expressas nos artigos que compõem a obra $\mathrm{O}$ Federalista. Além dessa, também foram temas recorrentes questões econômicas e tributárias (MADISON; JAY; HAMILTON, 2001).

Por essas razões especiais, os referidos autores escreveram e encaminharam aos representantes das antigas colônias independentes uma série de artigos em que propuseram uma nova formulação de um Estado federal, com uma maior concentração de poder no organismo central do que a existente à época da Confederação:

\footnotetext{
1 Três ou quatro Confederações (JAY, 2001). "Publius".
} 


\begin{abstract}
Embora [o federalismo] tenha sido teorizado para fortalecer o governo central, o meticuloso cuidado com o qual isso se deu demonstra uma precisa e consciente vontade de conferir-lhe alguns poderes, mas de simultaneamente limitá-los àquilo que se considerasse essencial ao funcionamento da União. Por toda a obra dos federalistas, é possível perceber o apreço que se tinha pela ideia de liberdade e pela consciência de que, apesar de ter sido necessário conferir certos poderes à entidade central, era preciso cuidado para não sustentar um governo despótico. (ARAUJO, 2015, p. 66).
\end{abstract}

A obra dos federalistas ${ }^{2}$ foi a criação de uma forma de organização do Estado destinada a centralizar na União (poder federal) alguns poderes tido como importantes à garantia da segurança e sobrevivência dos Estados (poderes estaduais), mas tiveram a preocupação de evitar um governo despótico - que rejeitavam por analogia à Inglaterra Imperial - que pudesse a concentrar demasiados poderes e suprimir a autonomia dos Estados federados (TOCQUEVILLE, 2005).

Dessa explanação, percebe-se que a existência de uma descentralização políticoadministrativa não implica na existência de um modelo federativo. Este é um sistema intermediário entre a descentralização absoluta - que poderia ser exemplificado pelo modelo grego de Cidade-Estado - e a centralização total - do qual é exemplo o absolutismo do Antigo Regime (DALLARI, 1998).

O caminho da obra do federalismo pode partir de qualquer desses extremos em direção a um ponto intermediário. Por essa razão, o federalismo pode ser um modelo centralizador quando parte de um sistema descentralizado - da Confederação à Federação, como houve nos Estados Unidos; ou um modelo descentralizador quando parte de um sistema centralizado - do Império unitário à Federação, como no Brasil (BARACHO, 1986).

Essa percepção explica por que a organização do Estado "não tem de ser necessariamente uma ordem centralista e pode [...] abrir caminho a uma distribuição de competências e poderes a nível horizontal e vertical, caracterizando-se pela descentralização" (SILVA; ALVES, 2013, p. 592). Pode haver algum grau de descentralização administrativa em Estados unitários mesmo que suas subdivisões não tenham autonomia e competência de auto-organização.

\footnotetext{
2 Como ficaram conhecidos genericamente James Madison, John Jay e Alexander Hamilton, autores da obra
} 
Percebe-se que o federalismo é apenas um veículo da (des)centralização administrativa, uma situação atual que nada indica acerca do objetivo pretendido. Esse sistema pode ser utilizado como no Brasil, para descentralizar o poder, ou como nos Estados Unidos, para centralizar um pouco o poder. O objetivo do federalismo pode servir tanto a fins centralizadores como a fins descentralizadores, a depender da situação originária que se pretenda reformar. Apesar disso, é comumente - e não inteiramente sem razão relacionado ao movimento descentralizador.

\section{PARADIGMAS HISTÓRICOS: A CENTRALIZAÇÃO NA FRANÇA E A DESCENTRALIZAÇÃO NOS ESTADOS UNIDOS DA AMÉRICA}

A miscelânea da civilização brasileira - em que pese ser lugar comum - não se limitou aos colonos portugueses, aos povos nativos, aos negros escravizados ou aos imigrantes europeus (mais recentemente). Além dessa miscigenação etnológica, o Brasil, especialmente no período histórico cuja abordagem se trabalha, teve seu desenvolvimento político e cultural moldado por influências, principalmente, da França e dos Estados Unidos da América.

Ao se abordar a influência francesa no Brasil não se refere às invasões ocorridas no Rio de Janeiro e no Maranhão ocorridas sobretudo no século XVI (embora alguns esparsos conflitos tenham ocorrido até o século XIX) em que pese sua importância histórica (GAFFAREL, 1878).

A animosidade com a França pacificou-se após a queda de Napoleão Bonaparte na Batalha de Waterloo, em 1815. A partir de então se fortaleceu a influência da alta cultura francesa em Portugal e em suas colônias. Já em 1816 chegava ao Brasil a Missão Artística Francesa, contratada com o objetivo de instalar no Rio de Janeiro uma academia de artes e ciências ${ }^{3}$.

\footnotetext{
${ }^{3}$ Em que pese este objetivo nunca tenha sido efetivado.
} 
A influência cultural francesa se contrapõe à influência política dos Estados Unidos da América. Essa aproximação com os norte-americanos, entretanto, somente se fortaleceu durante o segundo reinado, após a exoneração de José Bonifácio, quem, à época de ministro dos negócios estrangeiros, deu pouca atenção aos Estados Unidos (COSTA, 1999).

As relações entre os dois países viria a se estreitar a partir do Segundo Reinado, quando houve aprofundamento da influência norte-americana no pensamento político brasileiro. As instituições americanas - dentre elas o federalismo - eram apreciadas e comumente invocadas nos debates legislativos em meados do século XVII. Pensadores como Alexis de Tocqueville $(2005 ; 2013)$ e os federalistas James Madison, John Jay e Alexander

Hamilton (2001) não raro eram invocados para sustentar ou refutar determinadas $\operatorname{propostas}^{4}$.

\subsection{A centralização da França durante o Antigo Regime e sua continuidade}

A cultura francesa fascinava os brasileiros. Mas também no âmbito político havia uma grande admiração pelas instituições francófonas. Por essa razão, é de grande importância um estudo sobre a distribuição de competências administrativas naquele país, a fim de se descobrir o grau de centralização praticado.

A história francesa à época era bastante conturbada. Após a Revolução de 1789 a 1799, o Antigo Regime caiu e, logo em seguida, em 1804, ascendeu o Primeiro Império Francês, sob tutela do autoproclamado Imperador Napoleão Bonaparte.

A organização administrativa da França, apesar das reviravoltas políticas, permaneceu em boa medida como fora durante o Antigo Regime: "As instituições do Antigo Regime que, em número muito maior do que se supõe, foram transportadas para a nova sociedade geralmente perderam nessa passagem seus nomes, mesmo quando conservaram as formas" (TOCQUEVILLE, 2013, p. 47).

\footnotetext{
${ }^{4}$ Como, por exemplo, o fez o primeiro Marquez de Caravellas (José Joaquim Carneiro de Campos), em discurso proferido em 16 de junho de 1832, ao invocar a obra de Alexander Hamilton para contribuir a sua proposta de alteração de alguns artigos da Constituição de 1824. Essa proposta culminaria no Ato Adicional de 1834, a ser abordado oportunamente (MARQUEZ DE CARAVELLAS, 1914, p. 333).
} 
Durante o Antigo Regime, cada província da França era administrada por um intendente geral $^{5}$ que se reportava ao chamado Conselho do Rei. Eram trinta intendentes, geralmente membros da baixa nobreza, que reuniam em si todo o poder administrativo, à revelia dos governadores e dos parlamentos. Elaboravam relatórios nos quais requeriam alguma atenção dos Conselheiros à província (TOCQUEVILLE, 2013).

Aquele Conselho, formado por herdeiros da antiga aristocracia feudal, fixava alguns impostos, como a talha - que era a principal imposição à época - e a forma de repartição da receita entre as províncias. Outros impostos eram instituídos e cobrados diretamente pela realeza, sem intervenção dos conselheiros (DELALANDE; SPIRE, 2010).

As antigas elites feudais permaneceram com seus títulos nobiliárquicos e seus privilégios estamentais. Entretanto, retirou-se-lhes os poderes que tinham sobre suas províncias, e nenhuma outra autoridade lhes veio substituir: o governo central de Paris assumira a responsabilidade pelo cuidado com os pobres, pelos arranjos agrícolas e pela construção de estradas, por exemplo: "É fácil concluir que uma caridade feita de tão longe freqüentemente era cega ou errática e quase sempre muito insuficiente" (TOCQUEVILLE, 2013, p. 49).

Nos anos que antecederam a Revolução Francesa, tamanha concentração do corpo social, dizia-se que Paris “já era a própria França" (TOCQUEVILLE, 2013, p. 81). A capital do reino exercia uma forte influência sobre as demais províncias, e crescia em proporções que preocupavam a realeza. As províncias menores ficavam cada vez mais despovoadas à medida que a população com melhores condições financeiras migrava para Paris (TOCQUEVILLE, 2013).

Em 1740, Montesquieu, em carta dirigida ao Abade Nicolini, da cidade de Florença, disse esperar a visita de um outro amigo (chamado Cerati) e mencionou que: "[...] through that occasion [ele, seu amigo, poderia] enjoy a better view of France, in which there is nothing worth the seeing but Paris, and the distant provinces, because the latter have not as yet been devoured by the former"6 (MONTESQUIEU, 1777, p. 8-9).

\footnotetext{
5 Embora igualmente existissem ministros em cada província, a competência destes era bastante reduzida, e na prática era o intendente geral quem realizava as principais tarefas financeiras e administrativas.

6 "Naquela ocasião [ele, seu amigo, poderia] aproveitar uma melhor visão da França, segundo a qual há apenas Paris e as províncias distantes, porque estas ainda não foram devoradas por aquela", em tradução livre.
} 
Diversos exemplos são usados por Alexis de Tocqueville para demonstrar suas conclusões quanto ao domínio da centralização em Paris sobre o restante da França. Um interessante, percebido e descrito em um relatório elaborado acerca do comércio de livros aponta que, durante os séculos XVI e XVII, havia na França diversos editores e gráficas espalhados pelas províncias. No século XVIII, em que pese "se publicassem infinitas vezes mais escritos" (TOCQUEVILLE, 2013, p, 83), não haviam mais gráficas nas províncias, e as que existiam apenas remetiam tudo o que partia de Paris.

Outro sintoma da centralização em Paris foi a facilidade com a qual a Assembleia Constituinte da Revolução Francesa conseguiu eliminar, em um único ato, todas as províncias da França - algumas muito mais antigas que a própria monarquia - e reorganizar o reino em oitenta e três novas unidades, "como se fossem o solo virgem do Novo Mundo" (TOCQUEVILLE, 2013, p. 84). Sobre esse evento lamentou Edmund Burke:

\begin{abstract}
The artists of the French Revolution had given their very first essays and sketches of robbery and desolation against his territories, in a far more cruel "murdering piece" than had ever entered into the imagination of painter or poet. Without ceremony, they tore from his cherishing arms the possessions, which he held for five hundred years, undisturbed by all the ambition of all the ambitious Monarchs who, during that period, have reigned in France 7 . (BURKE, 1999, p. 227).
\end{abstract}

A força da centralização na França absolutista, durante a Revolução, e mesmo após esta, demonstra que o povo francês era refém de Paris e de quem a dominasse. A estrutura interna do poder se manteve estável mesmo com os eventos revolucionários, e o exercício desse poder, que era absoluto antes da Revolução, não perdeu muito de sua força com o advento desta. Permaneceu centralizada a França.

\title{
a. O federalismo norte-americano e a influência de sua descentralização
}

O federalismo - como realidade e como teoria política - surgira na recentemente independente nação norte-americana quando perceberam que precisavam as treze excolônias se unirem sob um governo unitário para se fortalecerem.

\footnotetext{
7 "Os artistas da Revolução Francesa haviam demonstrado seus primeiros ensaios e esboços de pilhagem e de devastação contra seus territórios em uma "obra de assassinato" muito mais cruel do que qualquer pintor ou

poeta jamais pôde imaginar. Sem cerimônia, eles retalharam as possessões dos braços daqueles que delas cuidaram por quinhentos anos sem terem sido perturbados nem por toda a ambição de todos os mais ambiciosos Monarcas que reinaram sobre a França durante esse período", em tradução livre
} 
Diante do temor de uma nova reação britânica à independência, as colônias, logo após o término da Guerra de Independência Americana, em 1783, convocaram uma reunião que ficou conhecida como Convenção da Filadélfia, em 1787. Inicialmente designada apenas para reformar alguns artigos do tratado confederativo, a Convenção acabou por, ao contrário,

deliberar sobre a fundação de um novo Estado norte-americano, ao que foi promulgada a Constituição dos Estados unidos da América, em 1787.

A América, a partir daquele momento, passaria a ser estruturada sob os auspícios de uma Constituição e não mais de um Tratado. Deixaria de lado uma frágil aliança de Estados para consolidar uma estreita ligação entre o povo. Estava formada a federação norte-americana. (LIMA, 2011, p. 128).

Nos anos que sucederam a consolidação do federalismo norte-americano, nos termos preconizados por seus fundadores, Alexis de Tocqueville (2005) realizou profundo estudo das instituições no novo mundo.

Antes de expor suas conclusões acerca da influência da descentralização administrativa veiculada pelo federalismo nos Estados Unidos, Alexis de Tocqueville (2005) diferencia centralização administrativa e centralização governamental. Esta seria a concentração da competência para tratar de assuntos gerais e se relacionar com povos estrangeiros. A primeira seria a centralização da competência para inclusive tratar de assuntos específicos de certas localidades, ou seja, aquilo que diz respeito às províncias apenas, e que podem ser diversos e contrapostos, conforme cada caso.

A centralização administrativa seria, para Tocqueville (2005), a reunião de meios operacionais para dirimir interesses eminentemente locais de modo uniforme por uma autoridade central. Retira-se da localidade (não apenas do poder público, mas da sociedade em si) o poder de auto-regulação em benefício de um ente central superior:

Vimos que nos Estados Unidos não havia centralização administrativa. Lá, mal encontramos o indício de uma hierarquia. A descentralização foi levada a um grau que nenhuma nação europeia seria capaz de suportar, penso eu, sem profundo mal- estar, e que inclusive produz efeitos importunos. Mas, nos Estados Unidos, a centralização governamental existe no mais alto grau. Seria fácil provar que a potência nacional está mais concentrada aí do que foi em qualquer das antigas monarquias da Europa. (TOCQUEVILLE, 2005, p. 100).

Percebe-se que, embora o movimento federalista americano tenha surgido como forma de centralizar o poder outrora disperso nas soberanias dos estados confederados, as

Revista Brasileira de História do Direito| e-ISSN: 2526-009x | Brasília | v. 2 | n. 1 | p. 44 - 62 | Jan/Jun. 2016. 
atribuições desse ente central foram muito bem pensadas e delimitadas. Esta foi a preocupação esposada pelos teóricos do federalismo James Madison, John Jay e Alexander Hamilton (2001).

$\mathrm{O}$ poder central norte-americano ficou encarregado dos mais altos interesses nacionais, como por exemplo os direitos exclusivos de constituir exército, celebrar paz e declarar guerra, firmar tratados com outras nações e organizar o sistema monetário. São as principais competências que caracterizam a centralização governamental.

Referente à descentralização administrativa, o povo norte-americano exercia o poder por meio das comunas (townships) compostas geralmente por dois a três mil habitantes. Não se encontraria a administração pública concentrada nem mesmo nos Estados federados. A estes caberia apenas a representação do exercício da administração, enquanto esta seria efetivamente realizada pelas comunas. Acerca da quase absoluta descentralização administrativa:

O que mais chama a atenção do europeu que percorre os Estados Unidos é a ausência do que, em nosso países, chamamos governo ou administração. Na América, vemos leis escritas; percebemos sua execução cotidiana; tudo se move à nossa volta e não descobrimos em parte alguma o motor. A mão que dirige a máquina social escapa a cada instante. (TOCQUEVILLE, 2005, p. 82).

A fluidez com que a administração norte-americana se executava decorria da inexistência de hierarquia ou organismos centrais. As comunas cuidavam da execução das leis Estaduais e de assuntos locais como saúde pública, policiamento, avaliação da qualidade das escolas ou expedição de licenças.

Em decorrência dessa descentralização administrativa, Alexis de Tocqueville (2005) aponta que o governador do Estado era tido como mero representante do poder executivo, pois só lhe competia o exercício de alguns dos poderes que atualmente lhe são próprios. Em síntese, suas atribuições eram voltadas a representar a administração perante o Legislativo estadual.

O estudo das instituições federalistas norte-americanas influenciou tanto a doutrina federalista de Aureliano Cândido de Tavares Bastos (1997) como a doutrina do conservador Visconde do Uruguay (1865a). Por curiosidade, enquanto nos Estados Unidos o federalismo fora desenvolvido para centralizar o governo outrora confederado, no Brasil o sistema se propôs ao inverso: descentralizar o poder do Império. Por ser assunto de importância nodal para o presente estudo, será objeto de aprofundamento a seguir. 


\section{ORIGEM DO PENSAMENTO FEDERALISTA NO BRASIL IMPÉRIO E O ATO ADICIONAL DE 1834}

Parte da doutrina entende que a primeira manifestação de federalismo no Brasil se deu com o regime das capitanias hereditárias: "[...] Nascendo o Império da federação das velhas capitanias[...]"(TÔRRES, 1964, p. 66) ou mesmo com a elevação do Brasil a Reino Unido a Portugal e a Algarves, situação na qual existiria um: "laço federativo que unia a tríplice coroa de D. João VI" (TÔRRES, 1964, p. 60).

Em atinência ao conceito de federação exposto alhures, percebe-se que não se pode considerar essas manifestações de relativa descentralização como se um sistema federativo fossem. Não havia nesses modelos uma autonomia dos entes plurais nem um relacionamento entre si, apenas uma pequena desconcentração administrativa com subordinação a um poder geral superior.

É difícil precisar exatamente quando surgiram os sentimentos federalistas no Brasil. Ocorre que, em virtude da extensão do Império e da dificuldade de fiscalização e imposição da lei geral, as províncias exerciam, de fato, competências que lhes eram formalmente vedadas (BASTOS, 1870).

À medida que o governo geral buscou limitar esse exercício de fato das províncias, começaram a surgir sentimentos revoltosos contrários à centralização administrativa: a Insurreição Pernambucana (1817) e a Confederação do Equador (1824) foram importantes revoltas infladas pelo sentimento de adotar um sistema federativo (ou confederativo, no caso da última) que assegurasse às províncias a desejada autonomia:

As condições da Província, nos fins de 1823, propendiam francamente para o ressurgimento do velho espírito republicano, agora acentuadamente impregnado da tendência federativa, já antiga, mas, na ocasião, incentivada pelas ameaças centralizadoras de Pedro I, que vinham fazer perigar $o$ sentimento autonomista, muito arraigado na região (HOLANDA, 1993, p. 277).

Esse sentimento não se acalentaram com a repressão dos revoltosos. Em 1831, D. Pedro I, em discurso proferido na cidade de Ouro Preto, então capital da província de Minas Geraes, no dia 22 de fevereiro daquele ano, demonstrou preocupação com o crescente sentimento federalista e com os desejos de reformar a então vigente Constituição de 1824 . Abdicaria em 7 de abril daquele ano (VISCONDE DO URUGUAY, 1865a).

Revista Brasileira de História do Direito| e-ISSN: 2526-009x | Brasília | v. 2 | n. 1 | p. 44 - 62 | Jan/Jun. 2016. 
Diante da abdicação de D. Pedro I, partidários do federalismo vislumbraram a possibilidade de instituição desse sistema no Brasil. Inicia-se, nesse momento, um relato histórico do trâmite das propostas de reforma da Constituição para instituir o federalismo no Brasil.

Já em maio daquele ano, logo no início da sessão legislativa, na Câmara dos Deputados, foram apresentados diversos requerimentos de reforma da Constituição de 1824, seguindo o rito próprio estipulado em seu art. 174.

Em 9 de julho de 1831 foi apresentado o projeto de reforma da Constituição elaborado pela competente comissão encarregada. Dentre as principais propostas, destacam-se a adoção de uma monarquia federativa (artigo único, $\S 1^{\circ}$ ), o fim do Poder Moderador $\left(\S 2^{\circ}\right)$ e do Conselho de Estado $\left(\$ 8^{\circ}\right)$, eleição e fim da vitaliciedade dos senadores $\left(\$ 5^{\circ}\right)$, criação de Assembleias Legislativas Provinciais $\left(\$ 9^{\circ}\right)$ e a autonomia fiscal e financeira das Províncias $\left(\$ 10^{\circ}\right)$ (VISCONDE DO URUGUAY, 1865b). O projeto da Câmara dos Deputados foi aprovado com modificações ${ }^{8}$ em relação ao texto original, em terceira discussão, no dia 12 de outubro de 1831, e foi remetido ao Senado para continuidade das deliberações (VISCONDE DO URUGUAY, 1865b).

Nesta casa legislativa permanente, se começou a discutir o projeto recebido no dia 18 de maio de 1832, e em 24 de julho do mesmo ano fora aprovado com diversas alterações ${ }^{9}$ que desagradaram a Câmara (VISCONDE DO URUGUAY, 1865b).

Houve ainda nova redação à proposta oriunda da Câmara para adequá-la ao rito estabelecido pela Constituição de 1824: o projeto originário já trazia em si as propostas finais pleiteadas com a reforma quando, na verdade, pelo processo constitucional, deveriam tão somente deliberar sobre quais artigos da Constituição deveriam ser alterados, para que se desse à legislatura seguinte, quando da nova eleição, mandato com os poderes necessários a tal fim. Era este o rito do art. 176 da Constituição de $1824^{10}$, como foi demonstrado no parecer final do Senado (VISCONDE DO URUGUAY, 1865b).

\footnotetext{
8 Entre as mudanças propostas pela redação final da Câmara dos Deputados, destacam-se: a adoção de uma Monarquia Federal, o fim do Poder Moderador, fim da vitaliciedade dos senadores, fim do Conselho de Estado, criação de Assembleias Legislativas Provinciais, separação das receitas provinciais da receita geral e adoção de uma regência una (VISCONDE DO URUGUAY, 1865b).

9 Dentre as emendas que modificaram o projeto original, destacam-se a supressão das seguintes propostas: Monarquia Federativa, fim do Poder Moderador, fim à vitaliciedade dos senadores e de extinção do Conselho de Estado (VISCONDE DO URUGUAY, 1865b).

10 Em virtude da importância desse fato, transcreve-se na íntegra o dispositivo referido: “Admittida a discussão, e vencida a necessidade da reforma do Artigo Constitucional, se expedirá Lei, que será sanccionada, e promulgada pelo Imperador em forma ordinária; e na qual se ordenará aos Eleitores dos Deputados para a seguinte Legislatura, que nas Procurações lhes confiram especial faculdade para a pretendida alteração, ou reforma." (Art. 176 da Constituição de 1824).
} 
Em 4 de setembro de 1832, a Câmara rejeitou as alterações do Senado e requereu uma sessão conjunta entre as duas Casas Legislativas para deliberação final sobre o projeto de reforma da Constituição (VISCONDE DO URUGUAY, 1865b).

Os senadores compareceram à sessão conjunta e os membros de ambas as Casas deliberaram de 17 a 28 de setembro de 1832, ao que foi aprovada a Lei de 12 de outubro de 1832, que conferiu poderes à legislatura seguinte para promover as alterações constitucionais, conforme o rito constitucional vigente (VISCONDE DO URUGUAY, $1865 b)$.

Já na seguinte legislatura, a Câmara dos Deputados, em 6 de maio de 1834, instalou a Comissão para Reforma da Constituição, que apresentou seu projeto de reforma em 7 de junho daquele ano. Após três discussões, que envolveram a apresentação de diversas emendas, foi apresentada, em 4 de agosto de 1834, a redação final da reforma, e aprovada no dia 6 de mesmos mês e ano (VISCONDE DO URUGUAY, 1865b). Foi aprovado o Ato Adicional, como ficou conhecida a Lei de 12 de agosto de 1834.

\section{A AUTONOMIA FINANCEIRA DAS PROVÍNCIAS E A CRISE DO FEDERALISMO FISCAL NO IMPÉRIO: EM BUSCA DA REPARTIÇÃO DE RECEITA}

Com o Ato Adicional de 1834, em sua redação final, o Brasil não chegou a se tornar, como pretendiam muitos políticos e pensadores da época, uma Monarquia Federativa. Ainda assim, promoveu uma grande descentralização nas atribuições administrativas das províncias.

Conforme a redação original da Constituição de 1824, reconhecia a importância da participação da sociedade civil nas decisões políticas da sua localidade, representada pela província (art. 71). Seu âmbito de atuação, entretanto, não condizia com o suposto reconhecimento da importância dessas deliberações.

Todo o Poder Legislativo estava concentrado na Assembleia Geral, formada pela Câmara dos Deputados e pelo Senado (arts. 13 e 14). Às províncias apenas competia deliberar sobre assuntos de interesse local, sem todavia exercer atividade legislativa. 
É no estudo das finanças do Império que se compreende melhor sua excessiva centralização. Apenas a Câmara dos Deputados tinha competência para criar impostos - juntamente com o orçamento anual - e as províncias sobreviviam mediante um precário sistema de repartição da receita geral, como será aprofundado oportunamente.

Lei $\mathrm{n}^{\circ} 99$ de 31 de outubro de 1835, responsável por prever o orçamento relativo aos anos de 1836 a 1837, também estipulou as imposições tributárias a serem recolhidas pelo governo geral naquele período (art. 11). Às Assembleias Provinciais competia, em consonância com o atribuído no Ato Adicional, a criação de quaisquer imposições não compreendidas nas atribuições gerais ${ }^{11}$ (art. 12), especialmente sobre importação ${ }^{12}$.

A Constituição de 1824 estatuía norma que fundamentaria o embrionário e vindouro princípio da anualidade tributária ${ }^{13}$, segundo a qual a lei orçamentária deveria prever todas as despesas e toda a receita esperada do ano fiscal, inclusive com discriminação de suas fontes derivadas, como os impostos (art. 172). A cada ano, com edição de nova lei orçamentária, poderia haver modificação na competência tributária das províncias como consequência da expansão da competência geral.

Isso ocorria porque o Ato Adicional de 1834 vedava a imposição de exações tributárias pelas províncias sobre artigos já tributados pelo governo geral (art. 10, $5^{\circ}$ ), além de imposições sobre importação (art. 12). Não havia um sistema de competências tributárias comuns ou concorrentes ${ }^{14}$ como o que existe na atualidade.

As províncias possuíam apenas competência residual ou subsidiária diante do governo geral. A cada ano, aquilo que este decidisse tributar estaria imediatamente excluído das possibilidades provinciais, o que demonstra uma fragilidade em sua autonomia financeira.

\footnotetext{
11 As províncias não podiam instituir imposições sobre matérias tributadas pelo governo geral para não lhe prejudicar a arrecadação. Por essa mesma razão, também era vedada a tributação que recaia sobre a Fazenda geral: "A Fazenda geral não pode ser obrigada aos impostos provinciaes ou municipaes, nem a quaesquer outras despezas decretadas por leis provinciaes." (VISCONDE DO URUGUAY, 1865a, p. 377). Percebe-se claramente que é esse o embrião da imunidade tributária recíproca prevista no art. 150, VI, "a" da CF/88, embora à época somente se aplicasse à Fazenda Geral.

12 .

importação não apenas o ingresso de produtos oriundos do exterior, mas também aqueles provenientes de outras províncias (BASTOS, 1870). A vedação à cobrança de tributos sobre o ingresso de produtos originários de outras províncias já demonstra uma preocupação com a liberdade de tráfego, que hoje foi transformado em princípio constitucional pelo art. $150, \mathrm{~V}, \mathrm{CF} / 1988$

13 Que viria a ser suprimido pela Constituição Federal de 1988, em benefício do princípio da anterioridade (art. 150, III, alínea "b", CF/1988).

14 Essa fórmula problemática foi reproduzida no Decreto $1^{\circ}$ de 15 de novembro de 1889 , do Marechal Deodoro da Fonseca, que instituiu a "Republica Federativa" (art. $2 \$ 4^{\circ}$ do referido Decreto).
} 
Vedada a imposição sobre artigos já tributados pelo governo geral, o Ato Adicional de 1834 atribuiu às Províncias a competência para organizar seus próprios orçamentos e instituir tributos visando a financiar suas despesas. $\mathrm{O}$ governo geral poderia vetar o orçamento provincial, mas não poderia propor alterações sob risco de interferir na função legislativa provincial (DOLHNIKOFF, 2005).

As novas rendas das províncias nãos lhes proporcionaram uma arrecadação suficiente para custear os novos encargos que lhes foram atribuídos com a reforma. A pressa na aprovação das medidas descentralizadoras resultou em um precário sistema de distribuição tanto de competências tributárias como de repartição de receitas (FERREIRA, 1999).

O orçamento e a balança financeira das províncias brasileiras antes do Ato Adicional de 1834 eram, em geral, positivos. Apesar da ausência de autonomia tributária e administrativa, a arrecadação fiscal das províncias por meio dos impostos gerais era suficiente para suprir suas atribuições.

Aqueles impostos que eram arrecadado na província, apesar de instituídos pela Assembleia Geral, revertiam à receita das respectivas localidades. Apenas uma parcela era revertida ao tesouro nacional, que por sua vez poderia ser destinada ao auxílio de outras províncias em dificuldades financeiras. Isso não quer dizer que houvesse uma abundância de recursos nas províncias, apenas aponta que elas, em sua generalidade, não costumavam sofrer de déficits financeiros.

Em um relatório apresentado ao Imperador D. Pedro I pelo então Ministro da Fazenda Nogueira da Gama, pode-se verificar que a maioria das províncias do Brasil possuía um saldo financeiro positivo. Apenas as províncias de Minas Geraes, Goyaz, Matto Grosso, Santa Catharina e Espírito Santo possuíam déficits orçamentários ${ }^{15}$, enquanto a Bahia possuía apenas um pequeno - e por isso preocupante - superávit ${ }^{16}$ (GAMA, 1823).

\footnotetext{
15 As despesas das seguintes províncias superavam suas receitas nos respectivos valores aproximados: Minas Geraes em 60:000\$000 (sessenta mil contos de réis); Goyaz em 20:000\$000 (vinte mil contos de réis); Matto Grosso em 10:000\$000 (dez mil contos de réis); Santa Catharina em 34:000\$000 (trinta e quatro mil contos de réis) e o Espírito Santo em 33:000\$000 (trinta e três mil contos de réis) (GAMA, 1823).

16 A receita da Bahia superava sua receita na pequena quantia aproximada de 3:700\$000 (três mil e setecentos contos de réis) (GAMA, 1823)
} 
Infelizmente, não foi possível realizar uma análise comparativa entre as despesas provinciais originárias e as novas despesas oriundas das atribuições impostas pelo Ato Adicional de 1834: "se poderá estranhar a falta de noções claras, e circunstanciadas do estado da Fazenda Publica de cada huma das Provincias deste Imperio: por vezes se tem exigido, e de muito poucas tem vindo com a clareza, e individuação necessarias" (GAMA, 1823, p. 3). A falta de técnica adequada pelas províncias prejudica o estudo presente.

As novas atribuições atribuídas às províncias por ocasião da reforma constitucional solaparam o equilíbrio orçamentário de outrora. É que a descentralização de atribuições promovida pelo Ato Adicional não foi coordenada com a devida repartição de competência tributária.

O impacto orçamentário do Ato Adicional fez com que muitas províncias não dispusessem mais de receita suficiente a custear as novas atribuições. A título exemplificativo pode-se elencar as províncias de Minas Geraes e Bahia, cuja arrecadação apenas cobria um terço das suas despesas (VISCONDE DO URUGUAY, 1865a).

Teve o Cofre Geral de vir-lhes em socorro: a lei de 22 de outubro de 1836 determinou que se fizesse repartição de receita entre todas as províncias que não conseguissem custear suas despesas, no valor limite do estipulado pela última lei orçamentária antes do Ato adicional, a lei de 8 de outubro de 1833.

No ano seguinte, em 1837, a lei de 11 de setembro daquele ano repartiu entre onze províncias o montante de 580.000\$000 (quinhentos e oitenta contos de réis); em 1838, a lei de 30 de outubro fez repartir entre as mesmas 11 províncias a quantia de $380.000 \$ 000$ (trezentos e oitenta contos de réis); e em 1839, a quantia aumentou para 669.000\$000 (seiscentos e sessenta e nove contos de réis), que seriam divididos entre as onze províncias mais as de Alagoas, Parahyba, Maranhão e Ceara, totalizando quinze províncias. Naquele orçamento, apenas as províncias do Rio de Janeiro, São Paulo e Rio Grande do Sul não receberam receita do governo central.

Assim, depois do feita a divisão da ronda geral e provincial, e de emancipadas financeiramente as Provincias, no que era provincial, forão quasi iodas suppridas pela renda geral pela espaço de 13 annos.

Era esta a natural e inevitável consequência da maneira viciosa por que fora feita a divisão da renda[...]" (VISCONDE DO URUGUAY, 1865a, p.249). 
A fundação do federalismo fiscal no Brasil, embora bem intencionada, não foi devidamente planejada e sistematizada. Desde sua instituição - às pressas por medo de rebeliões separatistas - o modelo descentralizador atribuiu às províncias a desejada autonomia fiscal. Essas novas possibilidades, entretanto não foram suficientes para suprir os custos adicionais das novas competências assumidas.

Esses problemas surgidos com o Ato Adicional de 1834, ainda se fazem presentes hoje, embora com outras facetas e paradigmas. É que, mesmo atualmente, não se superou esse problema de harmonização do federalismo fiscal com uma saudável repartição de receitas, o que vem a fragilizar a aclamada e reafirmar o poder do governo geral.

\section{CONCLUSÃO}

A influência francesa no Brasil, tanto no aspecto cultural como político, inspirou a centralização administrativa que caracterizou o período Imperial - sobretudo o Primeiro Reinado e o período Regencial. Em que pese a forte influência da centralização administrativa no Brasil, aos poucos o espírito descentralizador - inspirado pela doutrina norte-americana - se fortaleceu, vindo a inspirar a primeira tentativa de implantação do federalismo no Brasil.

Após a abdicação de D. Pedro I, em 1831, foi apresentada a primeira proposta de alteração da Constituição de 1824 com fim de instaurar um regime federalista no Brasil, ao atribuir autonomia administrativa e financeira às Províncias. Esta proposta, que culminou na promulgação do Ato Adicional de 1834.

Nessa reforma constitucional, as Províncias tornaram-se competentes para legislar sobre impostos próprios, excluídos aqueles de competência do Governo Geral (o que hoje se denomina Governo Federal), bem como autonomia para gerir e dispor sobre suas finanças.

Entretanto, a má distribuição de competências, somada a um deficitário sistema de repartição de receitas (que dependia da Lei Orçamentária do Governo Geral), acabou por impedir a concretização da sonhada autonomia financeira provincial.

Percebe-se que o começo do federalismo fiscal e da autonomia financeira dos entes federados, no Brasil, surgiu já com muitos dos problemas que persistem à contemporaneidade. Problemas como a repartição de receita, a guerra fiscal entre os entes

Revista Brasileira de História do Direito| e-ISSN: 2526-009x | Brasília | v. 2 | n. 1 | p. 44 - 62 | Jan/Jun. 2016. 
que viria a inspirar o início das deliberações sobre a liberdade de tráfego, hoje princípio constitucional -, ou mesmo a atribuição de competências já eram preocupações que pairavam sobre os assuntos legislativos, e que ainda não foram completamente solucionadas.

\section{REFERÊNCIAS}

ARAUJO, Guilherme Dourado Aragão Sá. A influência da doutrina norte-americana no federalismo de Aureliano Candido de Tavares Bastos. In: LIMA, Martonio Mont'Alverne Barreto; ALBUQUERQUE, Newton de Menezes (coords.). Temas de Pensamento Constitucional Brasileiro IV. Belo Horizonte: Arraes Editores, 2015.

BARACHO, José Alfredo de Oliveira. Teoria geral do federalismo. Rio de Janeiro: Forense, 1986.

BASTOS, Aureliano Candido de Tavares. A provincia: estudo sobre a descentralisação no Brazil. Rio de Janeiro: B. L. Garnier, 1870.

BURKE, Edmund. Selected works of Edmund Burke: letters on a regicide peace. Indianapolis: Liberty Fund, 1999. 3. v.

COSTA, Emilia Viotti da. Da Monarquia à República: momentos decisivos. 6. ed. São Paulo : UNESP, 1999.

DALLARI, Dalmo de Abreu. Elementos de teoria geral do Estado. 20. ed. São Paulo: Saraiva, 1998.

DELALANDE, Nicolas; SPIRE, Alexis. Histoire sociale de l'impôt. Paris: La Découverte, 2010.

DOLHNIKOFF, Miriam. O pacto imperial: origens do federalismo no Brasil. São Paulo: Globo, 2005.

FERREIRA, Gabriela Nunes. Centralização e descentralização no Império: o debate entre Tavares Bastos e o visconde de Uruguai. São Paulo: Editora 34, 1999.

GAFFAREL, Paul. Histoire du Brésil Français au seizième siècle. Paris: Maisonneuve et cie., 1878.

GAMA, Manuel Jacinto Nogueira da. Exposição do estado da Fazenda Pública. Rio de Janeiro: Typographia Nacional, 1823.

HOLANDA, Sérgio Buarque de. História geral da civilização brasileira. Rio de Janeiro : Bertrand Brasil, 1993, 2. v. 
JAY, John. Concerning dangers from foreign force and influence. In: MADISON, James; JAY, John; HAMILTON, Alexander. The federalist: the Gideon edition. Indianapolis: Liberty Fund, 2001, p. 5-9.

LIMA, Rogério de Araújo. Os artigos federalistas: a contribuição de James Madison, Alexander Hamilton e John Jay para o surgimento do Federalismo no Brasil. Revista de Informação Legislativa, Brasília, a. 48, n. 192, out./dez., 2011.

MADISON, James; JAY, John; HAMILTON, Alexander. The federalist: the Gideon edition. Indianapolis: Liberty Fund, 2001.

MARQUEZ DE CARAVELLAS (José Joaquim Carneiro de Campos). Discurso na sessão de 16 de junho de 1832. In: BRAZIL. Annaes do Senado do Império do Brazil: segunda

sessão da primeira legislatura, de 27 de abril a 30 de junho de 1832. Rio de Janeiro: Senado Federal, 1914.

MONTESQUIEU, Charles Louis de Secondat, Baron de. The completed works of M. de Montesquieu: familiar letters ; miscellaneous pieces; the temple of Gnidus; a defence of the Spirit of Laws. London: T. Evans and W. Davis, 1777. 4. v.

SILVA, Daniela Sofia Gomes da; ALVES, André Azevedo. Secessão e federalismo na perspectiva da escola austríaca. MISES: Revista Interdisciplinar de Filosofia, Direito e Economia, São Paulo, v. 1, n. 2, jul./dez. 2013, p. 589-601.

TOCQUEVILlE, Alexis de. A democracia na América: leis e costumes de certas leis e certos costumes políticos que foram naturalmente sugeridos aos americanos por seu estado social democrático. 2. ed. São Paulo: Martins Fontes, 2005. 1. v.

O Antigo Regime e a Revolução. 2. tir. São Paulo: WMF Martins Fontes, 2013.

TÔRRES, João Camillo de Oliveira. A democracia coroada: teoria política do Império do Brasil. 2. ed. Petrópolis: Vozes, 1964.

VISCONDE DO URUGUAY. Estudos práticos sobre a administração das Províncias no

Brasil. Rio de Janeiro: B. L. Garnier, 1865a. 1. t.

Estudos práticos sobre a administração das Províncias no Brasil. Rio de Janeiro: B. L. Garnier, 1865b. 2.t. 